Western University

Scholarship@Western

Chemistry Publications

Chemistry Department

$12-19-2008$

\title{
Silole based acetylenes as advanced $\pi$-conjugated systems for optoelectronic applications
}

Brian Pagenkopf

University of Western Ontario, bpagenko@uwo.ca

Mahmoud M. Abd Rabo Moustafa

Follow this and additional works at: https://ir.lib.uwo.ca/chempub

Part of the Chemistry Commons

Citation of this paper:

Pagenkopf, Brian and Moustafa, Mahmoud M. Abd Rabo, "Silole based acetylenes as advanced $\pi$-conjugated systems for optoelectronic applications" (2008). Chemistry Publications. 54.

https://ir.lib.uwo.ca/chempub/54 


\title{
Silole Based Acetylenes as Advanced $\pi$-conjugated Systems for Optoelectronic Applications
}

\author{
Mahmoud M. Abd Rabo Moustafa and Brian L. Pagenkopf* \\ The University of Western Ontario \\ Department of Chemistry \\ 1151 Richmond Street \\ London, ON N6A 5B7 Canada
}

Keyword: Acetylenes, siloles, optoelectronic.

\begin{abstract}
Nonlinear optical (NLO) and electrooptical (EO) properties of $\pi$-conjugated systems have been the subject of intense interest during the past several decades. In this mini-review we focus on semi conducting materials based on alkyne $\pi$-conjugation, with particular emphasis on those examples from our laboratory of chromophores containing a silole core. Several closely related examples from the literature are also discussed.
\end{abstract}

\section{Introduction}

Nonlinear optical (NLO) and electrooptical (EO) properties of $\pi$-conjugated systems have been the subject of intense interest during the past several decades [1]. This field has been fuelled by the large number of potential applications for conjugated materials in electronic and electro-optical devices. The $\pi$-conjugated systems based on the alkyne functionality have long been a cornerstone for the formation of semiconducting materials since the monumental discoveries of highly conductive polyacetylene [2] and the topochemical solid-state polymerization of diacetylenes [3]. On the other hand, advances in alkyne chemistry are appearing at an astounding rate, and acetylenes now constitute a 
principal class of compounds nearly in all areas of chemistry; including synthetic organic, material, natural product and biochemistry [4].

Structural rigidity and electronic communication are the hallmarks of the acetylene functionality [4]. These attributes make alkynes a highly versatile component for conjugated scaffolds of conducting materials such as polyacetylenes 1, arylacetylenes macrocycles 2 [5] and arylene ethynylene framework 3 [6] (Figure 1). The successful development of these materials in functional devices will be facilitated by a richer understanding of the key aspects of their synthesis, electronic structure, and special properties, including film formation [4]. The fruits of these efforts include synthetic polymers with programmed solid-state organization and transition metal acetylides 4 (Figure 1) [7]. Poly arylene ethynylene (PAE) structures incorporating silole subunits 5 (Figure 1) provide yet another appealing avenue to these materials. Because of the current vast body of work on conjugated alkynes, in this brief review we draw largely upon the silole work from our own lab and will briefly discuss related compounds with well defined extended conjugation.

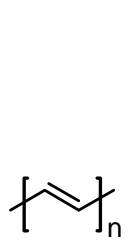

1

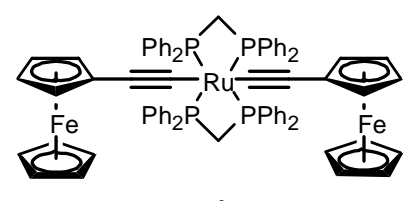

4

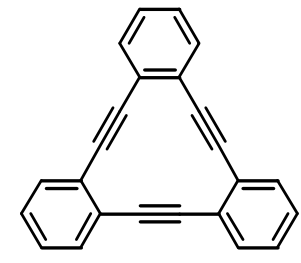

2

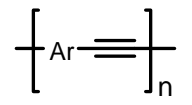

3

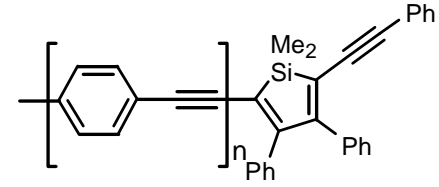

5

Figure 1: Examples of acetylene based $\pi$-conjugated semiconducting materials

\section{Silole Containing Polymers and Chromophores}

The chemistry of silole based $\pi$-conjugated systems has continued to receive much attention due to their potential as conducting materials for novel applications such as 
light-emitting devices [8], nitroaromatic sensors [9] and biosensors [10]. The unique electronic features of silole ring arise from its low-lying LUMO, which is substantially different from cyclopentadiene and other heterocycles. This particularly low-lying LUMO is due to the $\sigma^{*}-\pi^{*}$ conjugation between the $\sigma^{*}$ orbital of exocyclic Si-R bond and the $\pi^{*}$ orbital of the butadiene moiety on the ring [11]. Structural rigidity and electronic communication of the alkyne functionality beside the outstanding properties the silole ring encouraged us and others to explore the combination of siloles and alkynes in new, and hopefully, interesting ways. The sustained advancement of silole based acetylene chemistry lies in no small part from the pioneering efforts by the groups of Tamao and West to construct the silole ring, including the development of new synthetic methodology based on transition metal and metal acetylides, and meticulous exploration of silole properties has provided a solid foundation for others to build upon [12].

In 1997, Barton and co-workers utilized the versatile dibromo silole 6 [12] to synthesize the silole-acetylene polymers 7 and 8 [13]. If compared to the corresponding poly(phenyleneethynylene)s $\left(\lambda_{\max }=425 \mathrm{~nm}\right)[14]$ and poly (thiopheneethynylene)s $\left(\lambda_{\max }\right.$ $=438 \mathrm{~nm}$ ) [15], the silole-containing polymers significantly showed red-shifted absorptions implicating the importance of the silole ring in the properties of these substances.

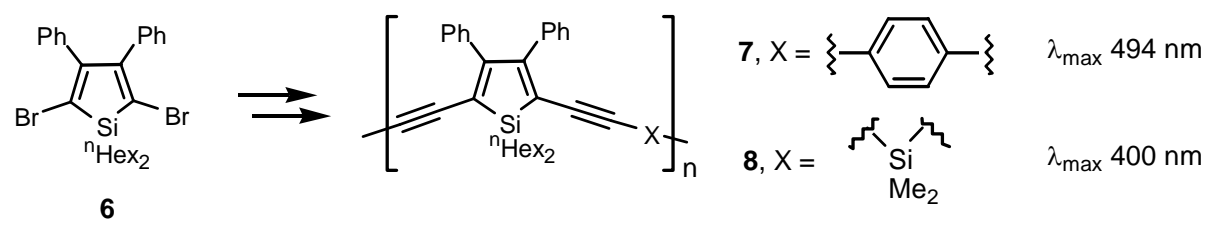

Figure 2: Absorption data for polymers in THF at room temperature

In 1998, Tamao and co-workers reported a series of 2,5-diethynylsilole monomers 9 and their polymers 10 (Figure 3) [16]. While PAE type polymers normally have relatively large bandgaps of about 2.1-2.6 eV, the synthesized diethynylsilole-based polymers significantly showed narrower bandgaps up to $1.8 \mathrm{eV}$. Also, an additional red-shift in the absorption spectrum was observed when diethynylthiophene moiety was incorporated. 
Despite the unique features of these novel siloles, the conductivities of the synthesized polymers upon doping with iodine were found to be moderate.
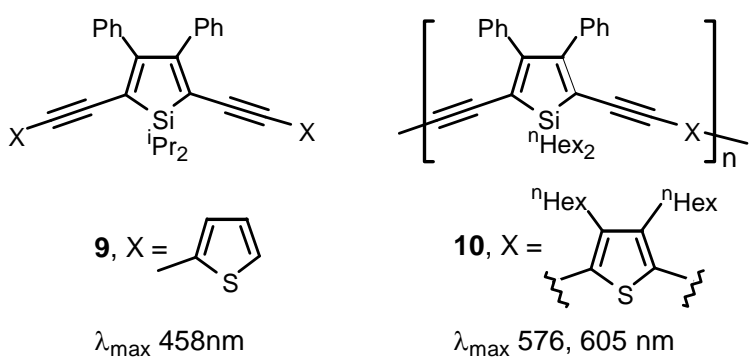

Figure 3: Absorption data for polymers in chloroform at room temperature

In the same year, Ohshita et al. reported polymers having 2,5-diethynylenesilole systems linked by an organosilicon bridge (e.g. 11, Figure 4) and demonstrated that these polymers exhibit an enhanced conjugation along the polymer backbone due to the presence of the silicon spacer. As a consequence, these polymers were presented as new class of conjugated polymers with small band gaps and high thermal stability [17].

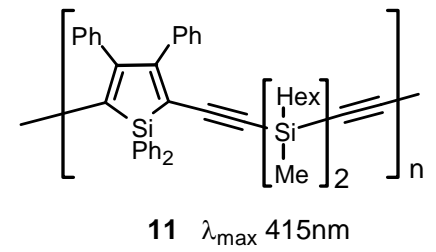

Figure 4: Absorption data for polymers in THF at room temperature

A classic way to fine tune the electronic properties of a chromophore is to modify substituents at the periphery, but the ability to vary the functional groups at the silole termini has been impeded by the challenges of synthesizing dissymmetric siloles[18]. Additionally, the synthesis of length-specific oligomers requires the use of a dissymmetric building block that can serve either as an end cap or as a starting point for iterative chain extension [19]. In this regard, we reported a more direct route to obtain the dissymmetric siloles 14 through site-specific cross-coupling methodology, utilizing $\mathrm{ZnCl}_{2}$ as an oxidizing agent for residual LiNaph [18]. The important consequence of using excess $\mathrm{ZnCl}_{2}$ was the presumed transmetallation of the silole (to give 13), which, compared to the dilithio-silole, is considerably less basic and less nucleophilic. This 
attenuation in activity allowed formation of a dissymmetric silole by clean monochlorination (16.2:1 ratio) using $N$-chlorophthalimide (NCP), and followed by iodination with $\mathrm{I}_{2}$ to afford the new chloroiodosilole 5 in $81 \%$ yield (Scheme 1)[18]. The synthesis of this strategic intermediate was a milestone step for us, and opened a new pathway toward structurally tuned silole chromophores and oligomeric siloles of precise composition.

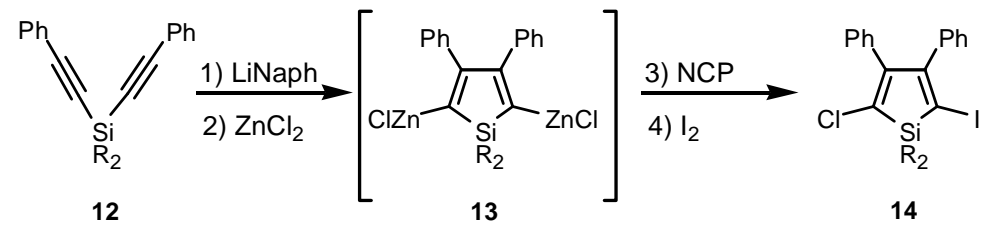

Scheme 1: Synthesis of dissymmetric silole building block

Working with 14 can be complicated by its high light sensitivity and instability, but a quick cross coupling of the more reactive iodide generally gives a stable chloro intermediate. And, this strategy was employed to successfully develop a direct, two-step and highly efficient sequence for the preparation of dissymmetric siloles. Therefore, insitu engagement of intermediate 14 in two successive cross-coupling reaction afforded the first silole-containing extended chromophores bearing electronically dissimilar functional groups at $\mathrm{C}(2)$ and $\mathrm{C}(5) \mathbf{1 5}$ (Figure 5)[18].

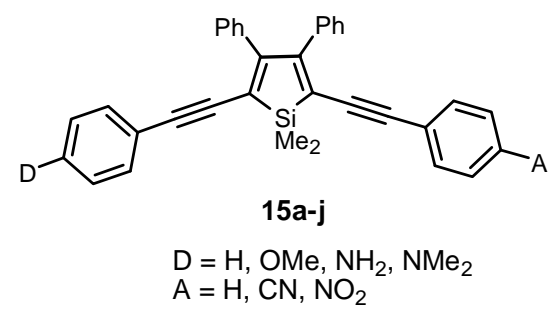

Figure 5: Donor- acceptor desymmetrized siloles

The electronic spectra of DA siloles 15a-j are shown in Table 1. A stepwise bathochromic shift was observed in the electronic absorption spectra from $429 \mathrm{~nm}$ (parent silole 15a) to $496 \mathrm{~nm}$ (the most polar silole 15j), indicating the important role of electron delocalization in theses substances which can be fine tuned by manipulation of peripheral 
push-pull substituents at the $\mathrm{C}(2)$ and $\mathrm{C}(5)$ positions. This synthetic advance made it possible to bring siloles into the family of electronically tuneable DA chromophores [18]. The consequences of varying the nature of the DA groups were also manifested in the photoluminescence spectra (table 1). Although it exhibited only the fifth longest wavelength absorption in this series, silole 15e displayed the longest wavelength emission, at $649 \mathrm{~nm}$. To the best of our knowledge, this is the longest wavelength emission for a compound possessing only a single silole in the chromophore. We suspect that dimerization of $\mathbf{1 5} \mathbf{j}$ is responsible for emission quenching. This communication constituted the first successful alkyne cross-couplings under Negishi conditions and demonstrated the ability to manipulate the electronic and physical properties of siloles through judicious combinations of peripheral functional groups.

Table 1: Summary of data of DA siloles determined in dichloromethane at room temperature.

\begin{tabular}{ccccc}
\hline Silole & Donor (D) & Acceptor (A) & $\begin{array}{c}\text { Absorption } \\
\lambda_{\max }\end{array}$ & $\begin{array}{c}\text { Emission } \\
\lambda_{\max }\end{array}$ \\
\hline $\mathrm{a}$ & $\mathrm{H}$ & $\mathrm{H}$ & 429 & 520 \\
$\mathrm{~b}$ & $\mathrm{OCH}_{3}$ & $\mathrm{H}$ & 435 & 528 \\
$\mathrm{c}$ & $\mathrm{OCH}_{3}$ & $\mathrm{CN}$ & 443 & 559 \\
$\mathrm{~d}$ & $\mathrm{NH}_{2}$ & $\mathrm{H}$ & 445 & 558 \\
$\mathrm{e}$ & $\mathrm{OCH}_{3}$ & $\mathrm{NO}_{2}$ & 456 & 649 \\
$\mathrm{f}$ & $\mathrm{NH}_{2}$ & $\mathrm{CN}$ & 457 & 594 \\
$\mathrm{~g}$ & $\mathrm{NMe}_{2}$ & $\mathrm{H}$ & 465 & 598 \\
$\mathrm{~h}$ & $\mathrm{NH}_{2}$ & $\mathrm{NO}_{2}$ & 471 & 613 \\
$\mathrm{i}$ & $\mathrm{NMe}_{2}$ & $\mathrm{CN}$ & 476 & 611 \\
$\mathrm{j}$ & $\mathrm{NMe}_{2}$ & $\mathrm{NO}_{2}$ & 496 & Not detectable \\
\hline
\end{tabular}

We also illustrated the importance and utility of the mixed silole $\mathbf{1 4}$ as a powerful intermediate for iterative oligomeric silole synthesis [19]. The crucial building block 16, obtained from 14, served either as an end cap or as a starting point for iterative chain extension to obtain a structurally homologous family of novel oligomeric chromophores 17a-d ( 
Figure 6).

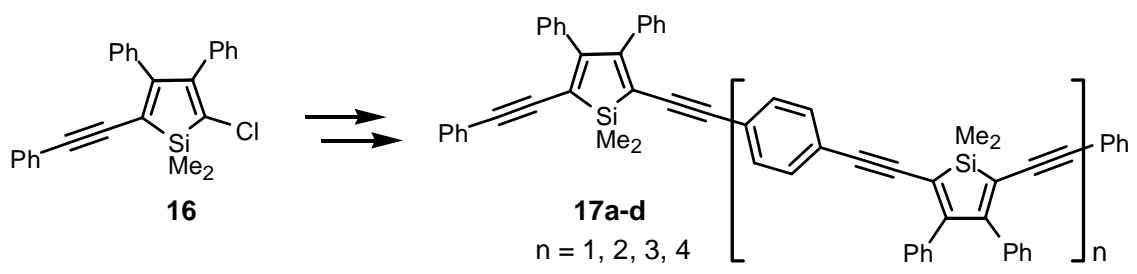

Figure 6: homologous family of novel oligomeric silolene chromophores

The electronic spectra of the oligomers $\mathbf{1 7}$ a-d are summarized in

Table 2. When compared to the analogous high molecular weight silole-containing polymers 7 (Figure 2), the relatively short tetramer 17c and pentamer 17d displayed similar absorption maximum. From these observations it appears that the effective conjugation length within the corresponding silole polymers was established for the first time, and that it was found to be approximately equal to that of the tetramer 17c [19]. On the other hand, the quantum efficiencies were modest with the monomer being most efficient at 9\%. Yet, the unprecedented molar absorptivities observed for these oligomers (extinction coefficients are greater than $120000 \mathrm{M}^{-1} \mathrm{~cm}^{-1}$ ) make them potential candidates for photovoltaic applications.

Table 2: Summary of data of oligomeric siloles 17, determined in dichloromethane at room temperature.

\begin{tabular}{cccc}
\hline Oligomer & n & $\begin{array}{c}\text { Absorption } \\
\boldsymbol{\lambda}_{\max }\end{array}$ & $\begin{array}{c}\text { Emission } \\
\boldsymbol{\lambda}_{\max }\end{array}$ \\
\hline $\mathrm{a}$ & 1 & 467 & 526 \\
$\mathrm{~b}$ & 2 & 479 & 543 \\
$\mathrm{c}$ & 3 & 492 & 550 \\
$\mathrm{~d}$ & 4 & 492 & 538
\end{tabular}

And to gain insight into the influence exerted by a single silole ring on the properties of an extended chromophore, we synthesized 18 (Figure 7) for direct comparison with its silole counterpart, trimer $\mathbf{1 7 b}$. The absorption and emission maxima 
of 18 were blue-shifted relative to $17 \mathbf{b}$, but interestingly the quantum efficiency is $20.11 \times 10^{-2}$ in the case of 18 versus $0.37 \times 10^{-2}$ for trimer $17_{\mathbf{b}}$ [19].
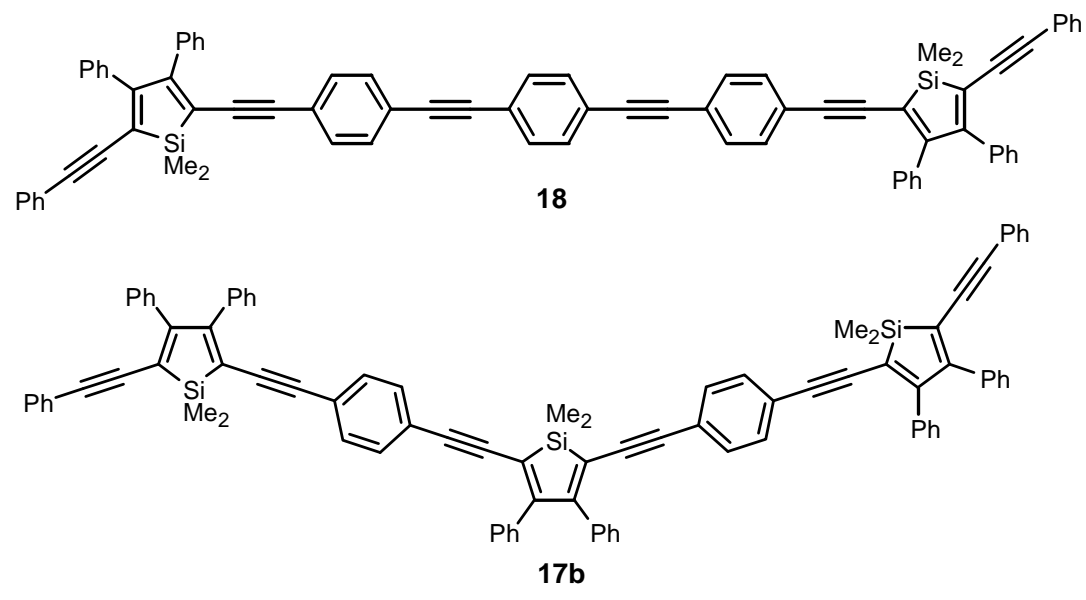

Figure 7: Trimer 17b and extended chromophore 18

These observations suggested that silole luminescence attenuation classically attributed to the 3,4-diphenyl rings can be overcome by manipulation of the steric bulk of the C2, C5, and Si substituents which would increase the energy barriers for nonemissive decay processes and ultimately result in increased photoluminescence. Thus, we investigated synthetically some silole modifications intended to impart "rigidity" or restricted rotation compared to the parent chromophore 15a. The outcome of this effort was the synthesis of the first highly luminescent 3,4-diphenylsilole chromophores 19 (Figure 8), having a quantum efficiency of $63 \%$ (determined with reference to fluorescin) [20]. When compared to that of 15a (quantum efficiency is 9\%) [18], this pioneering discovery welcomed siloles as promising structurally tunable luminophores and unambiguously refutes the notion that all 3,4-disubstituted siloles will possess intrinsically low quantum efficiencies.
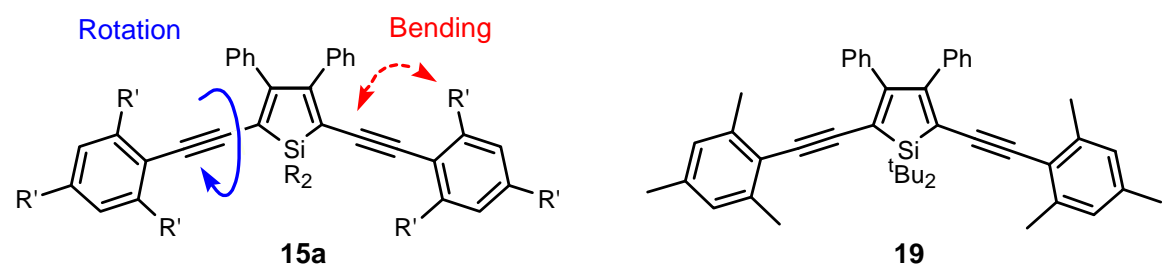

Figure 8: Sterically locked, highly luminescent silole 
The high quantum efficiency observed (at least) for this family of siloles motivated us to investigate their electrogenerated chemiluminescence (ECL) properties [21] and these compounds were found to be consistently more efficient fluorophores and generally exhibited greater radical ion stability than their ethylene substituted counterparts. While increasing steric protection in ethynyl compounds improves both fluorescence efficiency and radical ion stability, it attenuates that of ethylene counterparts [21].

In 2007, Ding et al. reported a series of 3,4-diphenylsiloles incorporating arylene ethynylene strands at the 2,5-positions (e.g. 20) [22]. Additionally, the effect of chain length on the photoluminescence properties was investigated. In comparison to our silole 18 (quantum efficiency is $20 \%$ ), double incorporation of arylene ethynylene strands in $\mathbf{2 0}$ (quantum efficiency is 50\%) was found to be effective for enhancing the photoluminescence. Also, elongation of the arylene ethynylene chain involving at least three aromatic rings led to high quantum yields even without any chemical modifications of the chain [22].

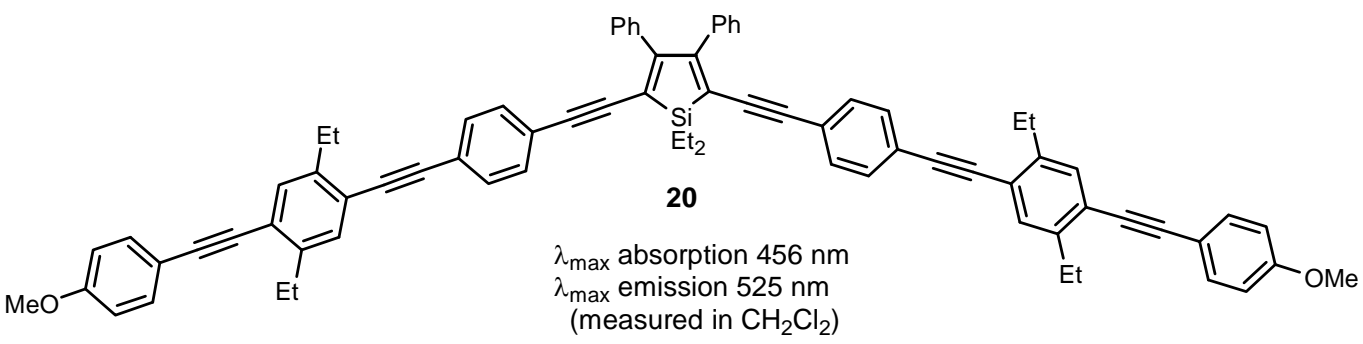

Figure 9: An example of Ding's siloles

In 2005, Wong et al. reported the synthesis and characterization of the first examples of a soluble, thermally stable, low-band gap, silole-containing platinum (II) polyynes 22 and the corresponding model monomer 21 [23]. Inclusion of the metal ethynyl unit resulted in intense $\pi-\pi^{*}$ trnsitions $\left(\lambda_{\max }=470\right.$ and 504 for 21 and 22 respectively) suggesting an intramolecular interaction between metal ethynyl units and silole rings that substantially perturbs the electronic structure of the parent silole unit [23]. In contrast, the quantum efficiencies dramatically decreased from the model compound $21(40 \%)$ to that of the polymer $22(10 \%)$. It was suggested that the reason for 
the poor PL observed with compound $\mathbf{2 2}$ may be the greater number of quenching sites and/or the possibility of bimolecular decay [23].
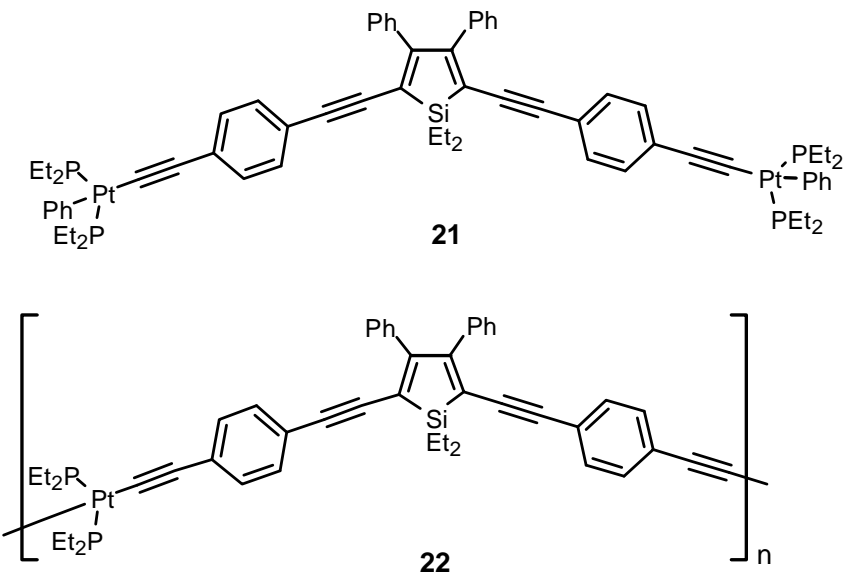

Figure 10: Polyplatinaynes siloles

Anionic siloles have been investigated as cyclopentadienyl ligand analogs [24], and recently Ohshita et al. reported the synthesis of related neutral $\mathrm{Fe}(\mathrm{CO})_{3}$-coordinated poly(disilanylene-3,4-diethynylenesiloles) 24 [25]. As expected, the coordination of $\mathrm{Fe}(\mathrm{CO})_{3}$ to the 3,4-diethynylsilole unit leads to significant changes in the polymer electronic states and the UV absorptions move to longer wavelength from those of the parent non-coordinated polymers $\mathbf{2 3}$, indicating the enhancement of p-conjugation by the $\mathrm{Fe}(\mathrm{CO})_{3}$-coordination. This red shift was attributed to the increase of the bond order between silole $\mathrm{C} 3-\mathrm{C} 4$ atoms, through which the two ethynyl groups may be conjugated more effectively [25].

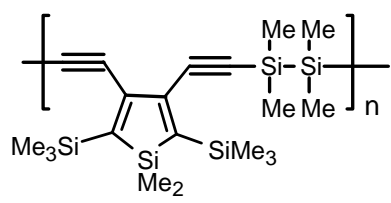

23

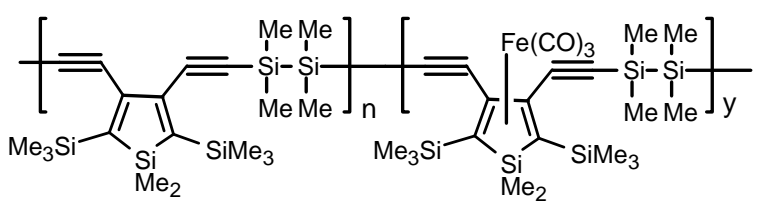

24

Figure 11: $\mathrm{Fe}(0)$-coordinated 3,4-diethynylsilole 
To know how substituent position about the silole ring affects the electronic states of $\mathrm{Fe}(\mathrm{CO})_{3}$-coordinated diethynylsilole-containing polymers, Ohshita and coworkers synthesized 2,5-diethynylsilole 25 (Figure 12) [26] to compare their properties with those of 3,4-diethynylsilole derivatives 27. Although, the non-coordinated compound 25 exhibited red-shifted absorptions relative to $27, \mathrm{Fe}(\mathrm{CO})_{3}$-coordination to 2,5diethynylsilole system in $\mathbf{2 6}$ led to blue-shifts of the absorption maxima. On the other hand, the absorption maxima of 3,4-diethynylsilole are red-shifted by $\mathrm{Fe}(\mathrm{CO}) 3$ coordination $\mathbf{2 8}$.
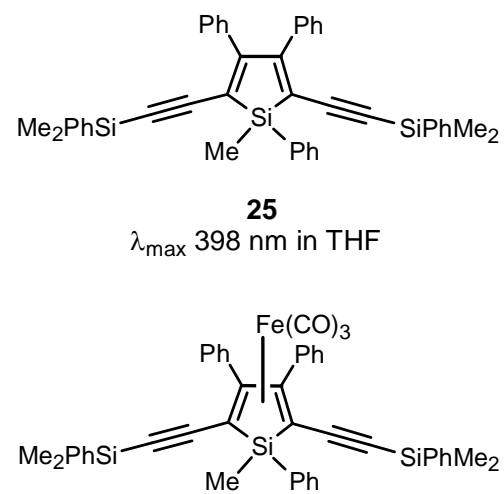

26 $\lambda_{\max } 307 \mathrm{~nm}$ in THF

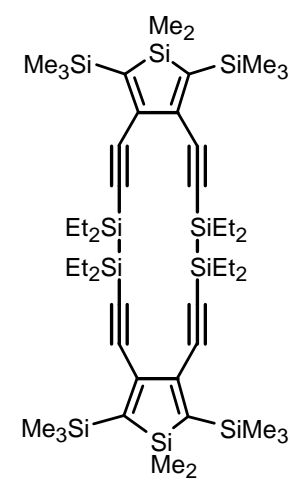

27

$\lambda_{\max } 301 \mathrm{~nm}$ in THF

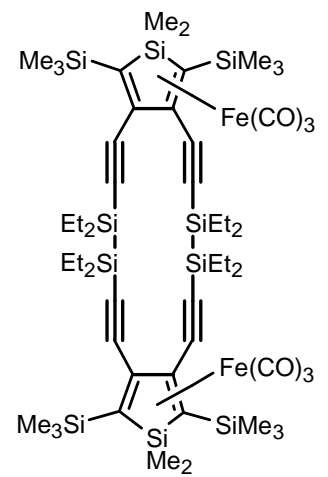

28

$\lambda_{\max } 320 \mathrm{~nm}$ in THF

Figure 12: $\mathrm{Fe}(0)$-coordinated 3,4- and 2,5-diethynylsilole

In 2001, a rare and fascinating example related to some of the silole systems described here was reported by Marder and coworkers, in which the reductive coupling of two butadiynes at a rhodium centre was utilized successfully to construct 2,5bis(arylethynyl)metallacyclopentadiene 29 (Figure 13)[27]. In addition to its stability, the high luminescence observed with this compound makes it an attractive system for further study as an emissive material in OLEDs. 


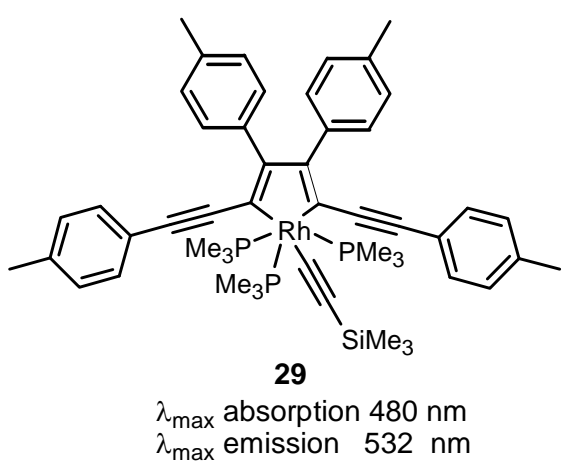

Figure 13: Marder's metallacyclopentadiene

\section{Conclusion}

The rapid advances in alkyne synthetic processes has facilitated an astounding abundance of new $\pi$-conjugated systems with fascinating properties and potential for materials applications in a variety of important areas, including NLO's, ECL and PV. This minireview has highlighted some of our work in this area focusing on those featuring a silole core, and some related systems were also discussed.

\section{Acknowledgments}

We thank the Natural Sciences and Engineering Research Council of Canada (NSERC) and the Egyptian Academy of Scientific Research and Technology for partial financial support.

\section{References}

[1] (a) T. A. Skotheim, R.L. Elsenbaumer, J. R. Reynolds, Handbook of Conducting Polymers, Marcel Dekker, New York, 2007;

(b) P. N. Prasad, D. J. Williams, Introduction to Nonlinear Optical Effects in Molecules and Polymers, Wiley, New York, 1991.

[2] C. K. Chiang, C. R. Fincher Jr., Y. W. Park, A. J. Heeger, H. Shirakawa, E. J. Louis, S. C. Gau, A. G. MacDiarmid, Phys. Rev. Lett. 39 (1977) 1098.

[3] G. Wegner, Pure Appl. Chem. 49 (1977) 443.

[4] F. Diederich, P. J. Stang, R.R. Tykwinski (Eds.), Acetylene Chemistry: Chemistry, Biology, and Material Science, Wiley-VCH, Weinheim, Germany, 2005.

[5] O. S. Miljanic, K. P. C. Vollhardt, G. D. Whitener, Synlett. (2003) 29. 
[6] (a) R. Giesa, Rev. Macromol. Chem. Phys. C36 (1996) 631;

(b) U. H. F. Bunz, Chem. Rev. 100 (2000) 1605.

[7] M. O. Wolf, J. of Inorg. and Organomet. Polym. and Mater. 16, 3 (2006) 189.

[8] (a) S. Yamaguchi, T. Goto, K. Tamao, Angew. Chem. Int. Ed. 39 (2000)1695;

(b) J. Chen, C. C. W. Law, J. W. Y. Lam, Y. Dong, S. M. F. Lo, I. D. Williams, D. Zhu, B. Z. Tang, Chem. Mater. 15(2003)1535;

(c) S. Yamaguchi, T. Endo, M. Uchida, T. Izumizawa, K. Furukawa, K. Tamao, Chem. Lett. 30(2001) 98;

(d) S. Yamaguchi, T. Endo, M. Uchida, T. Izumizawa, K. Furukawa, K. Tamao, Chem.-Eur. J. 6 (2000) 1683;

(e) M. Uchida, T. Izumizawa, T. Nakano, S. Yamaguchi, K. Tamao, K. Furukawa, Chem. Mater. 13 (2001) 2680;

(f) B.-H. Kim, H.-G. Woo, Organometallics 21(2002) 2796.

[9] (a) S. J. Toal, D. Magde, W. C. Trogler, Chem. Commun. 43(2005) 5465-54;

(b) H. Sohn, M. J. Sailor, D. Magde, W. C. Trogler, J. Am. Chem. Soc. 125 (2003), 3821;

(c) W. C. Trogler, Angew. Chem. Int. Ed. 40 (2001) 2104.

[10] C. Chan, M. Haeussler, B. Z. Tang, Y. Q Dong, K. Sin, W. Mak, D. Trau, M. Seydack, R. Renneberg, J. Immu. Meth. 295 (2004) 111.

[11] S. Yamaguchi, K. Tamao, J. Chem. Soc., Dalton Trans. 22 (1998) 3693.

[12] (a) K. Tamao, S. Yamaguchi, M. Shiro, J. Am. Chem. Soc. 116 (1994) 11715;

(b) S. Yamaguchi, R. Z. Jin, K. Tamao, M. Shiro, Organometallics 16 (1997) 2230;

(c) I. S.Toulokhonova, I. A. Guzei, R. West, J. Am. Chem. Soc.126 (2004)5336.

[13] W. Chen, S. Ijadi-Maghsoodi, T. Barton, Polym. Prepr. (Am. Chem. Soc., Div. Polym. Chem.) 38 (1997) 189.

[14] M. Moroni, J. Le Moigne, S. Luzzati, Macromolecules 27 (1994) 562.

[15] Y. Pang, Z. Wang, T. Barton, Polym. Prepr. (Am. Chem. Soc., Div. Polym. Chem.) 37 (1996) 333.

[16] S. Yamaguchi, K. Iimura, K. Tamao, Chem. Lett. (1998) 89. 
[17] J. Ohshita, N. Mimura, H. Arase, M. Nodono, A. Kunai, K. Komaguchi,M. Shiotani, M. Ishikawa, Macromolecules 31 (1998) 7985.

[18] A. J. Boydston, Y. Yin, B. L. Pagenkopf, J. Am. Chem. Soc. 126 (2004) 3724.

[19] A. J. Boydston, Y. Yin, B. L. Pagenkopf, J. Am. Chem. Soc. 126 (2004) 10350.

[20] A. J. Boydston, B. L. Pagenkopf, Angew. Chem. Int. Ed. 43 (2004) 6336.

[21] M. M. Sartin, A. J. Boydston, B. L. Pagenkopf, A. J. Bard, J. Am. Chem. Soc. 128 (2006) 10163.

[22] C. Ding, G. Babu, A. Orita, T. Hirate, J. Otera, Synlett 16 (2007) 2559.

[23] W.-Y. Wong, C.-K. Wong, S.-Y. Poon, A. W.-M. Lee, T. Mo, X. Wei, Macromol. Rapid Commun. 26 (2005) 376.

[24] (a) I. R. Butler, Organomet. Chem. 32 (2005) 375;

(b) I. R. Butler, Organomet. Chem. 31 (2004) 393.

[25] J. Ohshita, T. Hamaguchi, E. Toyoda, A. Kunai, K. Komaguchi, M. Shiotani, M. Ishikawa, A. Naka, Organometallics 18 (1999) 1717.

[26] J. Ohshita, H. Arase, T. Sumida, N. Mimura, K. Yoshimoto, Y. Tada, Y. Kunugi, Y. Harima, A. Kunai, Inorganica Chimica Acta 358 (2005) 4156.

[27] J.P. Rourke, A. S. Batsanov, J. A. K. Howardb, T. B. Marder, Chem. Commun.(2001) 2626.

[28] (a) Y. Zhao, S. C. Ciulei, R. R. Tykwinski, Tetrahedron Lett. 42 (2001) 7721, (b) S. C. Ciulei, R. R. Tykwinski, Org. Lett. 2, 23 (2000) 3607. 